Published by Al-Nahrain College of Medicine P-ISSN 1681-6579

E-ISSN 2224-4719

Email: iraqijms@colmed-alnahrain.edu.iq

http://www.colmed-alnahrain.edu.iq

http://www.iraqijms.net

Iraqi JMS 2019; Vol. 17(2)

\title{
Breast Cancer in a Sample of Yemeni Female Patients: Forensic Dermatoglyphic Traits and Clinico-Pathological Features
}

\author{
Mazen A. Bin Thabit ${ }^{1} M B C h B$, Naji A. Abdullah ${ }^{2} P h D$, Maysa S. Alnoban ${ }^{3} M P H$ \\ ${ }^{1}$ Pathology unit, ${ }^{2}$ Forensic Medicine Unit, ${ }^{3}$ Dept. of Community Medicine and Public Health, Faculty of Medicine and \\ Health sciences, Aden University, Yemen
}

\begin{abstract}
Background Breast cancer has a major impact on health of women worldwide and Yemen is not in exception. Fingerprints play an important role, which is highly individualistic and could be recognized as a powerful tool in diagnosis of various diseases, furthermore, their medico-legal importance.

Objective To study the clinico-pathological aspects of breast cancer and the role of fingerprints as screening test.

Methods Prospective study of 68 female patients with breast cancer came to modern histopathology laboratory - Aden during the period from January - June 2018. All the patients suffering from breast lumps were referred for Fine Needle Aspiration Cytology diagnosis as well as fingerprints of their both hands were taken.

Results Most of the participants (45.6\%) aged between $40-49$ years old, females from urban areas consisted $57.4 \%$, and about $51.5 \%$ of females in this study were illiterate. Females who had $1-3$ child consisted $33.8 \%$. Regarding the breast lump, $54.4 \%$ of females had tumor size $2-5 \mathrm{~cm}$, while skin change and fixed tumor to skin presented in same rate $(14.8 \%)$. No pain and no nipple discharge present in $85.2 \%$ and $91.2 \%$ respectively in females' study. The females with palpable axillary lymph nodes and right breast side tumor consisted the same percentage (58.8\%). Regarding the result of fine needle aspiration cytology, the invasive ductal carcinoma presented with high rate (85.3\%), while stage II present with $36.8 \%$. In relation to the finger print patterns; the loop patterns presented high rate in the little digit with $30.4 \%$, while whorls patterns presented in index digit in $33.6 \%$ of patients. The loops and whorls patterns revealed significant association with breast cancer with a P-value of 0.005 and 0.028 respectively.

Conclusion The social, behavioral, and hereditary factors play an important role in the development of breast cancer in addition to reproductive history, beside that the fingerprints are genetically determined factors that can be used as simple and cost-effective screening test for breast cancer.

Keywords Breast carcinoma, fingerprints, Dermatoglyphic, forensic, Yemeni female.

Citation

Bin Thabit MA, Abdullah NA, Alnoban MS. Breast Cancer in a sample of Yemeni female patients: forensic dermatoglyphic traits and clinico-pathological features. Iraqi JMS. 2019; 17(2): 135145. doi: 10.22578/IJMS.17.2.7
\end{abstract}

List of abbreviations: $B C=$ Breast cancer, $F N A C=$ Fine needle aspiration cytology, IDC = Invasive ductal carcinoma, ILC = Invasive lobular carcinoma () $\mathrm{WHO}=$ World Health Organization

\section{Introduction}

$\mathrm{B}$ reast cancer has a major impact on health of women worldwide. In both high and low resource countries, it is considered the most common malignancy and the second leading of cancer death in women and responsible for over one million of the estimated 10 million neoplasm diagnosed worldwide each year in both sexes. It is also the primary cause of cancer death among 
women globally, responsible for about 375,000 deaths in the year $2000^{(1,2)}$.

The World Health Organization (WHO) estimates that more than $60 \%$ of new cancer cases occur in low- and middle-income countries of Africa and Asia as well as central and south America (3).

Yemen is not an exception, in Sana'a / Yemen, a study of the patterns of malignancies among 1,491 patients found that, breast cancer (BC) ranked first among Yemeni women and formed $8 \%$ of all cancers ${ }^{(4)}$, on the other side; remote epidemiological studies in south eastern areas of Yemen, reported $B C$ as the most common cancer among women in Aden city and in south eastern areas of Yemen (between January 2002 and December 2006), according to the report of Aden Cancer Registry Center, 334 cases of females had breast cancer, and presented with $16.6 \%$ as first ranked cancer among over all sites and $30.3 \%$ in females ${ }^{(5)}$.

$\mathrm{BC}$ is a heterogeneous disease caused by interactions of both inherited and environmental risk factors that lead to progressive accumulation of genetic and epigenetic changes in BC cells ${ }^{(6)}$. Quality of life has become an important outcome measure in the treatment of cancer patients during the last decade. The adoption of western lifestyles and changes in diet has led to an increase in the number of overweight and obese women, as well as changing reproductive patterns, such as an earlier menarche, delayed childbearing, low parity, and decreased breastfeeding. These factors have been collectively described as "Westernization" and may have a significant impact on BC risk and prognosis (7,8). Arabs share common demographic features that include high rates of consanguinity, large family size and rapid population growth. There is a high frequency of autosomal recessive disorders and an increased frequency of homozygocity for autosomal dominant traits which have made certain disorders more prevalent in Arabs ${ }^{(9)}$.

Identification of women at increased risk for the development of $B C$ and the earliest possible diagnosis of patients with $B C$ should improve the results of $B C$ treatment. Genetic predisposition is one of the most intriguing factors associated with increased risk for breast cancer. Extensive studies identified the genetic link of breast cancer, and available evidence suggestion that family history of $\mathrm{BC}$ might be associated with a specific fingerprint ${ }^{(10-13)}$.

Fingerprint (dermatoglyphic/dactylography) is an impression of the friction ridge on all parts of the palms of the hands and soles of the feet; it came from two Greek words derma means (skin) and glyphs means (curves) (14). Dermatoglyphic is highly individualistic and makes up the basis form for personal identification in forensic examinations; Galton classified dermatoglyphic depending upon their primary patterns as loops, whorls, arches, and compound as seen in figure (1) ${ }^{(15)}$.

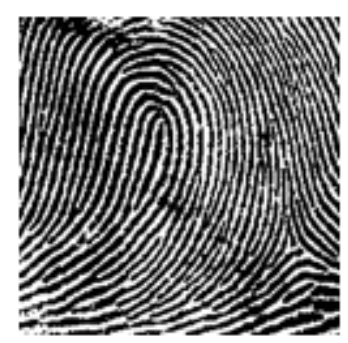

Left Loop

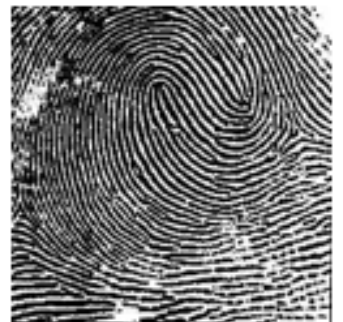

Right Loop

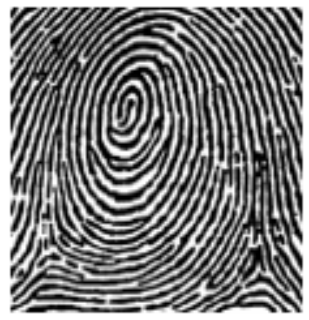

Whorl

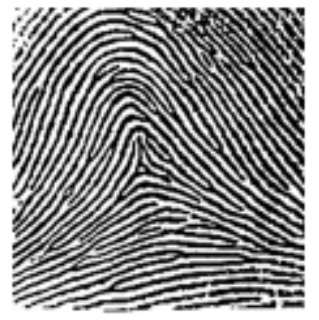

Arch

Figure 1. Different patterns of fingerprint 
These dermal ridge differentiation takes place early in fetal development, between $13^{\text {th }}$ to $19^{\text {th }}$ weeks of intrauterine life. The medicolegal importance of these patterns is unique and remain unchanged throughout life (16), these patterns may be affected by environmental factors in the first trimester of pregnancy, but after birth the patterns of fingerprints remain constant. The study of dermatoglyphic plays an important role and it's considered as a window of various diseases, and could be recognized as a powerful tool in the diagnostic features of certain psychological, medical, genetic, congenital malformation, and chromosomal disorders (17-19), and may be useful to study the genetic patterns in person and that used as a guide in the future screening of $\mathrm{BC}$ and represent a noninvasive anatomical marker of $B C^{(11,12,20)}$.

However, reports of dermatoglyphic patterns studies in patients with BC have been done by few workers as studies by Sridevi et al. (2010), Natekar et al. (2006), and Abbasi et al. (2006) have shown that finger print patterns were also affected in breast cancer, which is the commonest neoplastic disease in women, with a lifetime risk of $11-12 \%$ in the general population (21-23). In humans, the mammary buds begin to develop during the $6^{\text {th }}$ week, as solid down growths of the epidermis, into the underlying mesenchyme. These changes occur in response to an inductive influence from the mesenchyme. These dermal ridges develop in relation to the mammary buds take place early in fetal development, which are also formed by the $6^{\text {th }}$ week of gestation and they reach their maximum sizes between the $13^{\text {th }}$ to $19^{\text {th }}$ weeks of intrauterine life, this means that the genetic message which is contained in the genome normal or abnormal - is decoded during this period and it is also reflected by dermatoglyphics ${ }^{(24)}$.

The objective of the current study was to study is clinico-pathological aspects of $B C$ and the role of fingerprints as screening test.

\section{Methods}

This prospective study of 68 female patients with BC came to Modern Histopathology Laboratory from Aden and neighboring southern governorates of Yemen, during the period of January to June 2018, all the patients presented with breast lump were referred to Modern Histopathology Laboratory for fine needle aspiration cytology (FNAC) diagnosis. During the procedure of FNAC, patients have been asked after taking oral informed consent to fulfill data questionnaire including fingerprints.

Data were classified into different statistical variables including the demographic data (age, address and education level), risk factors (smoking, exercise, Khat chewing, fat diet, obesity, oral contraceptive pills, family history, and breast feeding), reproductive life (parity, age at menarche and age at menopause), clinical finding (lump, pain, size, location, breast side, consistency, fixation, skin changes, nipple discharge and palpable lymph nodes.

The fingerprint patterns were taken from female patients with BC at the Modern Histopathology Laboratory - Aden during the procedure of FNAC: The materials used in this study were as follows:

- A clean plain glass plate (3x5 inch) with blue ink.

- White papers.

- Good lighting and hand magnifying lens.

- Detergent with towel for cleaning the ink from the hand.

To take finger prints, the following method was used: First, press and roll the finger firmly on the ink area, then press thoroughly to print record card (white paper). Next, label each print "left" and "right" for the hands, afterwards, label each fingerprint with " $T$ " for thumb, "I" for index, " $M$ " for middle, " $R$ " for ring and " $\mathrm{L}$ " for little finger. Finally, all prints were analyzed by using magnifying lens. Finally, the FNAC result matched with histopathology result of the patients. All data were reviewed and analyzed by computer facility, using Microsoft and SPSS. Collected data were 
entered into an SPSS program and presented in frequency and percentage while Pearson's Chisquared test used to determine relations between categorical variables, and the level of statistical significance was taken as $P<0.05$, and presented in statistical tables.

\section{Results}

Sixty eight cases of female patients of $B C$ were studied during a period of $6^{\text {th }}$ months from January to June 2018 attending to Modern histopathology Laboratory - Aden for FNAC diagnosis, 31 (45.6\%) of females presented in age group 40-49 years old, while those females with age group $20-29$ and $\geq 60$ presented in equal rate $(10.3 \%)$, but the $B C$ of females at age $<20$ years old was not presented in the study. About $57.4 \%$ of female came from urban areas, while illiterate females consisted the high percentage of $\mathrm{BC}$ with $51.5 \%$, as shown in table (1).

Table 1. Demographic characteristics of breast cancer patients

\begin{tabular}{|c|c|c|}
\hline Character & No. (68) & $\%$ \\
\hline \multicolumn{3}{|l|}{ Age } \\
\hline$<20$ & None & 0.0 \\
\hline $20-29$ & 7 & 10.3 \\
\hline $30-39$ & 12 & 17.6 \\
\hline $40-49$ & 31 & 45.6 \\
\hline $50-59$ & 11 & 16.2 \\
\hline$\geq 60$ & 7 & 10.3 \\
\hline \multicolumn{3}{|l|}{ Address } \\
\hline City (Urban) & 39 & 57.4 \\
\hline Rural & 29 & 42.6 \\
\hline \multicolumn{3}{|l|}{ Education } \\
\hline University & 10 & 14.7 \\
\hline Secondary school & 10 & 14.7 \\
\hline Primary school & 13 & 19.1 \\
\hline Illiterate & 35 & 51.5 \\
\hline
\end{tabular}

In table 2, none of patients were smokers and all experience inactive life style. Obese females and those who took oral contraceptive pills consisted $25 \%$ and $27.9 \%$ respectively, and $64.7 \%$ of females breast feed their children. According to obstetrics and gynecology history; females with 1-3 child, menarche at age 13-14 years and menopause at age $46-50$ years were presented in $33.8 \%, 55.9 \%$ and $38.2 \%$ respectively.

Regarding the characteristics related to $\mathrm{BC}$, more than half of female participants (54.4\%) had tumor sized $2-5 \mathrm{~cm}$, the outer upper quadrant and hard consistency presented in $45.6 \%$ and $67.6 \%$ respectively, while central quadrant and soft consistency presented in equal rate $(7.4 \%)$. Majority of $\mathrm{BC}(85.2 \%)$ was not fixed without skin change and with no pain. Nipple discharge was presented only in $8.8 \%$ of participants female while no nipple discharge presented in $91.2 \%$ of female patients. Palpable axillary lymph nodes present in $58.8 \%$ of study females. Regarding the breast side tumor $(58.8 \%)$ present in the right side while $35.3 \%$ in the left side, as illustrated in table (3). 
Table 2. Distribution of patients by risk factors

\begin{tabular}{|c|c|c|}
\hline Character & No. (68) & $\%$ \\
\hline \multicolumn{3}{|l|}{ Habits } \\
\hline Smoking & None & 0.0 \\
\hline Exercises & None & 0.0 \\
\hline Fat diet & 12 & 17.6 \\
\hline Qat chewing & 10 & 14.8 \\
\hline Obesity & 17 & 25.0 \\
\hline Oral CCP & 19 & 27.8 \\
\hline Family history & 10 & 14.8 \\
\hline \multicolumn{3}{|l|}{ Breast feeding } \\
\hline Yes & 44 & 64.7 \\
\hline No & 24 & 35.3 \\
\hline \multicolumn{3}{|l|}{ Parity } \\
\hline Nullipara & 15 & 22.1 \\
\hline $1-3$ & 23 & 33.8 \\
\hline $4-6$ & 19 & 27.9 \\
\hline$>6$ & 11 & 16.2 \\
\hline \multicolumn{3}{|l|}{ Age at Menarche } \\
\hline$<12$ & 12 & 17.6 \\
\hline $13-14$ & 38 & 55.9 \\
\hline$>15$ & 18 & 26.5 \\
\hline \multicolumn{3}{|l|}{ Age at menopause } \\
\hline None & 35 & 51.5 \\
\hline $46-50$ & 26 & 38.2 \\
\hline$>50$ & 7 & 10.3 \\
\hline
\end{tabular}

Regarding the FNAC results, which were confirmed by histopathology study found that the invasive ductal carcinoma (IDC) presented with high rate $85.3 \%$, while medullary carcinoma presented with low rate $2.9 \%$. in relation to the clinical stage study, stage II presented in $36.8 \%$ of study females, while stage I and III presented in close rate $(26.5 \%$ and $27.9 \%)$ respectively and the rest of study females (8.8\%) present with stage IV, as shown in table (4).

Regarding the patterns of fingerprints in females with $B C$, the loop patterns presented were higher $(135,43.5 \%)$ than other patterns (whorls (113, 36.5\%) and arch (62, 20\%). Regarding the digit, the loop patterns (30.4\%) present in the little digit higher than other patterns, the whorls patterns presented in the index digit were higher than other patterns with $33.6 \%$ and arches patterns presented in thumb digit with $27.4 \%$. The three patterns (loops, whorls and arches) had significant association with BC ( $p$-value $=0.005,0.028$, and 0.011 respectively), as illustrated in table (5). 
Bin Thabit et al, Breast Cancer in Yemeni Female Patients

Table 3. Clinical finding of breast cancer patients

\begin{tabular}{|c|c|c|}
\hline Character & No. (68) & $\%$ \\
\hline \multicolumn{3}{|l|}{ Tumor size } \\
\hline$>2 \mathrm{~cm}$ & 17 & 25.0 \\
\hline $2-5 \mathrm{~cm}$ & 37 & 54.4 \\
\hline$>5 \mathrm{~cm}$ & 14 & 20.6 \\
\hline \multicolumn{3}{|l|}{ Quadrant } \\
\hline Outer upper & 31 & 45.6 \\
\hline Outer lower & 12 & 17.6 \\
\hline Inner upper & 12 & 17.6 \\
\hline Inner lower & 8 & 11.8 \\
\hline Central & 5 & 7.4 \\
\hline \multicolumn{3}{|l|}{ Consistency } \\
\hline Hard & 46 & 67.6 \\
\hline Firm & 17 & 25.0 \\
\hline Soft & 5 & 7.4 \\
\hline \multicolumn{3}{|l|}{ Fixation } \\
\hline Fixed & 10 & 14.8 \\
\hline Non fixed & 58 & 85.2 \\
\hline \multicolumn{3}{|l|}{ Skin changes } \\
\hline Yes & 10 & 14.8 \\
\hline No & 58 & 85.2 \\
\hline \multicolumn{3}{|l|}{ Pain } \\
\hline Yes & 10 & 14.8 \\
\hline No & 58 & 85.2 \\
\hline \multicolumn{3}{|l|}{ Nipple discharge } \\
\hline Yes & 6 & 8.8 \\
\hline No & 62 & 91.2 \\
\hline \multicolumn{3}{|c|}{ Palpable axillary Lymph nodes } \\
\hline Yes & 6 & 8.8 \\
\hline No & 62 & 91.2 \\
\hline \multicolumn{3}{|l|}{ Breast side } \\
\hline Right & 40 & 58.8 \\
\hline Left & 24 & 35.3 \\
\hline Bilateral & 4 & 5.9 \\
\hline
\end{tabular}


Iraqi JMS 2019; Vol. 17(2)

Table 4. Histopathology and clinical stage result of breast cancer patients

\begin{tabular}{ccc}
\hline \multicolumn{1}{c}{ Character } & No. (68) & \% \\
\hline Histology & & \\
Invasive ductal carcinoma (IDL) & 58 & 85.3 \\
Invasive lobular carcinoma (ICL) & 8 & 11.8 \\
Medullary carcinoma & 2 & 2.9 \\
\hline Clinical stage & & \\
In situ & None & 0.0 \\
Stage I & 18 & 26.5 \\
Stage II & 25 & 36.8 \\
Stage III & 19 & 27.9 \\
Stage IV & 6 & 8.8 \\
\hline
\end{tabular}

Table 5. Distribution of Patterns of finger print in different fingers of female with breast cancer

\begin{tabular}{ccccccc}
\hline \multirow{2}{*}{ Digits } & \multicolumn{2}{c}{ Loops } & \multicolumn{2}{c}{ Fingerprint patterns } \\
Whorls & \multicolumn{2}{c}{ Arches } \\
& No (\%) & p-value & No (\%) & p-value & No (\%) & p-value \\
\hline Thumb & $31(23)$ & 0.169 & $20(17.7)$ & 0.580 & $17(27.4)$ & 0.011 \\
Index & $23(17)$ & 0.228 & $38(33.6)$ & 0.028 & $7(11.3)$ & 0.784 \\
Middle & $37(27.4)$ & 0.113 & $19(16.8)$ & 0.428 & $12(19.4)$ & 0.216 \\
Ring & $3(2.2)$ & 0.169 & $20(17.7)$ & 0.580 & $15(24.2)$ & 0.051 \\
Little & $41(30.4)$ & 0.005 & $16(14.2)$ & 0.145 & $11(17.7)$ & 0.784 \\
\hline Total & $135(100)$ & & $113(100)$ & & $62(100)$ & \\
\hline
\end{tabular}

Note: 6 cases missed because had compound fingerprint patter

\section{Discussion}

Most epidemiological studies have evaluated risk factors for $B C$ in western populations. The epidemiology of $B C$ in most Asian populations is less well understood. Recent studies from several East Asian countries have shown that women in these countries increasingly share risk factors for $B C$ with women from western countries ${ }^{(7)}$. In Arab countries, BC accounts for $14 \%$ to $42 \%$ of all cancers in women ${ }^{(25)}$, and in Yemen BC was the first ranked cancer among overall cancer sites (16.6\%) and female cancers $(30.3 \%)^{(5)}$, Although the high incidence of BC in Yemen, there paucity of literature about the breast and certain epidemiological risk factors. Many studies, from many parts of the world, have looked at the prognostic value of age at diagnosis in patients with BC. After controlling for race, stage and treatment, it has been found that mortality due to $B C$ is greatest in younger women. About $45.6 \%$ of female patients in this study were in age group 40-49 years old, with mean age $44.2 \pm 1.68$ years old. This finding nearly similar to that seen in

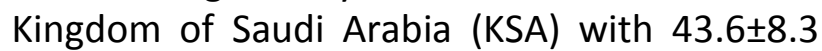
years old by Elkum et al. (2014) ${ }^{(26)}$, Najjar and Easson (2010), reported the mean age in Arab countries of $B C$ was $48 \pm 2.8$ years old (27). BC in this study is at age $<30$ years $(10.9 \%)$, this finding is more or less similar to that reported by Mehdi et al. (2016) in Omani women (6.2\%) (28), Egyptian women (8.19\%) ${ }^{(39)}$. More than half of our patients were from urban areas (57.4\%) unlike data published in Qatar were most of the patients were from rural areas $(88.7 \%)^{(30)}$. 
More than half of our patients (51.5\%) in this study were low educated, and $19.1 \%$ had finished primary school, while only $14.7 \%$ were highly educated (secondary school and university certificates). In Bangladesh, $87.67 \%$ of women with BC were at lower level of education (7) and according to study done in Qatar one third of women with $\mathrm{BC}$ at university level (30), while in $\mathrm{KSA}, 36.7 \%$ were illiterate, and those with higher level of education more than 12 years account only $12.4 \%$ (26). Education is an important factor of awareness against disease and highly educated females have a good awareness of early signs of BC.

A number of studies have observed that the association between smoking and the risk of developing BC may depend on the years of smoking, the lifetime amount of smoking, and the age at initiation, all females in this study were nonsmokers. Another study reported that half of the women had never smoked, and 20\% reported actively smoking one year before BC diagnosis. Although not statistically significant, the women who quit smoking after their BC diagnosis had $33 \%$ lower risk of death as a result of $\mathrm{BC}$ than did women who continued to smoke after diagnosis (31).

Obesity is now a common health problem worldwide. It is a lifestyle risk factor associated with not only high risk of cardiovascular and metabolic disease, but also with high incidence and poor prognosis of many malignant tumors. The correlation between general obesity and poorer prognosis of $B C$ may be mediated by increased circulating estrogen levels from excess adiposity through aromatase activity and reduced levels of sex hormone-binding globulins ${ }^{(32)}$. In this study, $25 \%$ of the cases with BC were obese. Many studies showed correlation between obesity and $B C$, one of them in $\mathrm{KSA}$; when $38.1 \%$ of women with $\mathrm{BC}$ were also obese ${ }^{(26)}$.

The relationship between oral contraceptive and cancer incidence is controversial, $27.9 \%$ of patients enrolled in this study with $\mathrm{BC}$ gave a history of previous oral contraceptive pills use. In Tehranian et al. (2010) study, 38.8\% of Iranian women with $\mathrm{BC}$ gave a history of previous oral contraceptive pills use and in other study $70.2 \%$ of Iranian women with BC gave a history of previous oral contraceptive pills use in comparison to control (52.2\%) (32), and these may signify that the use of oral contraceptive pills doubled the incidence of $B C$ (33).

In $\mathrm{BC}$, family history is a key risk factor of $\mathrm{BC} \mathrm{(}^{22-}$ 24). Women with a strong family history of $B C$ could inherit genetic alterations that modify their risk of disease. Several studies have demonstrated a relationship between $B C$ and other cancer cases in the family, with the prevalence of cancer cases ranging from 5 to $10 \%$ (34). In this study only $14.7 \%$ of the patients with $B C$ had a family history of $B C$. The family history of $B C$ (first degree relatives) had strong relation with $\mathrm{BC}$ or another cancer with 9.5\% and $13.3 \%$ respectively as reported in a study done in Pakistan (35), while high prevalence $(33.3 \%)$ of family history and BC was seen by Ribeiro et al. (34).

An association between lactation and protection from BC has also been postulated for a long time. The hypothesis that prolonged lactation protects against the development of $\mathrm{BC}$ is one of the oldest and the most enduring hypotheses concerning the etiology of this neoplasm. Age at menarche and BC risk are probably indirectly associated, research estimate that the risk of $\mathrm{BC}$ can be reduced 10$20 \%$ for each year menarche is delayed, the results of a large study revealed that for each two-year delay in one set of menstruation, BC risk was reduced by about $10 \%{ }^{(36)}$. In this study, most of the cases (55.9\%) were started menstruation between the age of 13-14 years old and only $17.6 \%$ started menarche at earlier age. Nearly similar figure of age at menarche of the women with BC in Karachi Pakistan (51.9\%) (37). The age of 13 years at first menarche was seen in (33.1\%) of Iranian women with BC (31). In this study, most of the patients (51.5\%) with BC were at pre-menopause; in a study conducted in different Arab countries to determine the age at diagnosis of BC in Arab nation, they found that the medium age was 44.5 years which was the pre-menopausal age (27). More than half of patients in this study present with breast lump of size range from 2-5 $\mathrm{cm}$ at the diagnosis (54.4\%), also the large size of $B C$ at the time of diagnosis was seen in Arab 
Palestine (33.6\%) compared to Jewish women (28.6\%) ${ }^{(6)}$. Upper outer quadrant and the right breast were the most common sites of $\mathrm{BC}$ involvement $(45.6 \%)$ and $(58.8 \%)$ respectively and bilateral was uncommon (5.9\%), also the right side was the commonest in Egyptian women $(52.7 \%)$ and bilateral involvement seen in $(0.3 \%)^{(29)}$. Histologically, most of the patient shows invasive ductal carcinoma (85.3\%) and only (11.8\%) was invasive lobular carcinoma, invasive ductal carcinoma was the commonest histological type of BC seen in Yemen by Harhra and Basaleem (2012) (38), and in Egyptians women invasive ductal carcinoma account $(81 \%)$ and invasive lobular carcinoma usually uncommon and account (13\%). In this study, most of the patient was at stage II clinically and pathologically (36.8\%), 33.6\% Arab Palestine women with $\mathrm{BC}$ are at stage II similar to Jewish (31.7\%) ${ }^{(6)}$. Stage III was the most common clinical stage seen by Harhra and Basaleem study (2012) done in Yemen $(43.3 \%)^{(38)}$.

It is suggested that many genes, which take part in the control of finger and palmar dermatoglyphic development, can also give indication to the development of premalignancy and malignancy. The specific BC predisposing genes are BRCA1, BRCA2 and p53. studies by Bowcock (1997), Easton et al. (1993), Shattuck et al. (1995) and Petty et al. (1997) ${ }^{(39-42)}$, all corroborate the finding that mutations in BRCA1 account for BC in $50 \%$ of families. In this study, the loop patterns of fingerprints were presented with $43.5 \%$ high than other patterns, and taken in consideration the distribution of patterns on digit we found the loop presented high in little finger accounting $30.4 \%$, while whorls presented high in index finger with $33.6 \%$ and arches presented in thumb with $27.4 \%$. All the three mentioned patterns had significant association with $\mathrm{BC}$ with $\mathrm{p}$-value $=0.005,0.028$, and 0.011 respectively. A study done by Abbasi et al. (2006) in Iran reported those women with BC had whorls pattern as a common fingerprint (23), while other study done by Srivdevi et al. (2010) and Natekar et al. (2006) founded the loop is the most common fingerprints in their participants ${ }^{(21,22)}$.
This study concluded that the social, behavioral, and hereditary factors play an important role in the development of BC. Yet the reproductive history is an important factor in the development of $\mathrm{BC}$ that signify the role of the hormones in the pathogenesis of $B C$, in addition to that, the genetic factors are still important and not well studied factors in $B C$ development. The medico-legal importance of these patterns is unique and remain unchanged throughout life, and the fingerprints are genetically determined factors that can be used as simple and cost-effective screening test for BC. Further study of fingerprints among high risk families matched with BARCA1 and BRCA2 genes is recommended to the validity of fingerprints as screening test of high-risk families.

\section{Acknowledgement}

The authors are grateful to the subjects who have voluntarily participated and extended kind cooperation during this laborious and time-consuming data collection.

\section{Author contribution}

Dr. Bin Thabit: performed the Introduction, data collection of (FNAC) and discussion. Dr. Abdullah: participated in the Data collection of (Printing the female patients' fingerprints) and method. Dr. Alnoban: Interpretation of results and statistical analysis.

\section{Conflict of interest}

The authors declare no conflict of interest.

\section{Funding}

Self- funding.

\section{References}

1. Saggu S, Rehman H, Abbas ZK, et al. Recent incidence and descriptive epidemiological survey of breast cancer in Saudi Arabia. Saudi Med J. 2015; 36(10): 1176-80. doi: 10.15537/smj.2015.10.12268.

2. Bray $F$, McCarron P, Parkin DM. The changing global patterns of female breast cancer incidence and mortality. Breast Cancer Res. 2004; 6(6): 229-39. doi: $10.1186 /$ bcr932.

3. Stewart BW, Wild CP. World Cancer Report. IARC, WHO. 2014; https://publications.iarc.fr/Non-SeriesPublications/World-Cancer-Reports/World-CancerReport-2014. 
4. Alsanabani JA, Gilan W, Saadi AA. Incidence data for breast cancer among Yemeni female patients with palpable breast lumps. Asian Pac J Cancer Prev. 2015;16(1):191-4. doi: 10.7314/apjcp.2015.16.1.191.

5. Ba Saleem HO, Bawazir AA, Moore $M$, et al. Five years cancer incidence in Aden Cancer Registry, Yemen (2002-2006). Asian Pac J Cancer Prev. 2010; 11(2): 507-11.

6. Zidan J, Sikorsky N, Basher W, et al. Differences in pathological and clinical features of breast cancer in Arab as compared to Jewish women in Northern Israel. Int J Cancer. 2012; 131(4): 924-9. doi: 10.1002/ijc.26431.

7. Iqbal J, Ferdousy T, Dipi R, et al. Risk factors for premenopausal breast cancer in Bangladesh. Int J Breast Cancer. 2015; 2015: 612042. doi: 10.1155/2015/612042.

8. Porter P. Westernizing women's risks? Breast cancer in lower income countries. N Engl J Med. 2008; 358(3): 213-6. doi: 10.1056/NEJMp0708307.

9. Najjar $\mathrm{H}$, Easson A. Age at diagnosis of breast cancer in Arab nations. Int J Surg. 2010; 8(6): 448-52. doi: 10.1016/j.ijsu.2010.05.012.

10. Gilligan SB, Borecki IB, Mathew S, et al. A family study of dermatoglyphic traits in India: A search for major gene effects on palmar pattern ridge counts. Am J Phys Anthropol. 1985; 68(3): 409-16. doi: 10.1002/ajpa.1330680312.

11. Katznelson MB, Bejerano $M$, Yakovenko $K$, et al. Relationship between genetic anomalies of different levels and deviations in dermatoglyphic traits. Part 4: Dermatoglyphic peculiarities of males and females with Down syndrome. Family study. Anthropol Anz. 1999; 57(3): 193-255.

12. Bierman HR, Faith MR, Stewart ME. Digital dermatoglyphics in mammary cancer. Cancer Invest. 1988; 6(1): 15-27.

13. Lynch HT, Albano WA, Heieck JJ, et al. Genetics, biomarkers, and control of breast cancer: a review. Cancer Genet Cytogenet. 1984; 13(1): 43-92.

14. Fields R, Molina DK. A novel approach for fingerprinting mummified hands. J Forensic Sci. 2008; 53(4): 952-5. doi: 10.1111/j.1556-4029.2008.00768.x.

15. Trapecar M, Balazic J. Fingerprint recovery from human skin surfaces. Sci Justice. $2007 ; 47(3)$ : 136-40. doi: 10.1016/j.scijus.2007.01.002.

16. Kaushal N. Fingerprints: Historical background and future trends. Int J Forensic Sci. 2010; 4(2): 30-4.

17. Mathew L, Hegde AM, Rai K. Dermatoglyphic peculiarities in children with oral clefts. J Indian Soc Pedod Prev Dent. 2005; 23(4): 179-82.

18. Bukelo MJ, Kanchan T, Unnikrishnan B, et al. Study of fingerprint patterns in children with acute lymphoblastic leukemia. Forensic Sci Med Pathol. 2011; 7(1): 21-5. doi: 10.1007/s12024-010-9190-9.

19. Sarvaiya S, Chaudhari J, Patel SV, et al. A study of palmar dermatoglyphic in leprosy in Bhavnagar District. Nat J Integ Res Med. 2011; 2(2): 46-9.

20. Seltzer $\mathrm{MH}$, Plato CC, Kathleen F. Dermatoglyphics in identification of Women Either with or at risk for breast cancer. Am J Med Genet. 1990; 37(4): 482-8. doi: 10.1002/ajmg.1320370412.

21. Sridevi NS, Delphine Silvia CR, Kulkarni $R$, et al. Palmar dermatoglyphics in carcinoma breast of Indian women. Rom J Morphol Embryol. 2010; 51(3): 547-50.

22. Natekar PE, DeSouza FM, Mothgare DD, et al. Digital dermal patterns in carcinoma of breast. Anthropologist. 2006; 8(4): 251-4. doi: https://doi.org/10.1080/09720073.2006.11890972.

23. Abbasi S, Einollahi N, Dashti N, et al. Study of dermatoglyphic patterns of hands in women with breast cancer. Pak J Med Sci. 2006; 22(1): 18-22.

24. Raizada A, Johri $V$, Ramnath $T$, et al. A cross-sectional study on the palmar dermatoglyphics in relation to carcinoma breast patients. J Clin Diagn Res. 2013; 7(4): 609-12. doi: 10.7860/JCDR/2013/4689.2864

25. Haddou Rahou B, El Rhazi K, Ouasmani F, et al. Quality of life in Arab women with breast cancer: a review of the literature. Health Qual Life Outcomes. 2016; 14: 64. doi: 10.1186/s12955-016-0468-9.

26. Elkum N, Al-Tweigeri T, Ajarim D, et al. Obesity is a significant risk factor for breast cancer in Arab women. BMC Cancer. 2014; 14: 788 . doi: 10.1186/1471-2407-14-788.

27. Najjar $H$, Easson A. Age at diagnosis of breast cancer in Arab nations. Int J Surg. 2010; 8(6): 448-52. doi: 10.1016/j.ijsu.2010.05.012.

28. Mehdi I, Monem EA, Al Bahrani BJ, et al. Age at diagnosis of female breast cancer in Oman: Issues and implications. South Asian J Cancer. 2014; 3(2): 101-6. doi: 10.4103/2278-330X.130442.

29. Farouk O, Awad M, Senbel A, et al. Breast cancer characteristics in very young Egyptian women $\leq 35$ years. Breast Cancer: Targets and Therapy. 2016; 8: 53-8. Doi: https://doi.org/10.2147/BCTT.S99350.

30. Donnelly TT, Al Khater AH, Al Kuwari MG, et al. Do socioeconomic factors influence breast cancer screening practices among Arab women in Qatar? BMJ Open. 2015; 5(1): e005596. doi: 10.1136/bmjopen-2014-005596.

31. Passarelli MN, Newcomb PA, Hampton JM, et al. Cigarette smoking before and after breast cancer diagnosis: mortality from breast cancer and smokingrelated diseases. J Clin Oncol. 2016; 34(12): 1315-22. doi: 10.1200/JCO.2015.63.9328.

32. Tehranian N, Shobeiri F, Pour FH, et al. Risk Factors for Breast Cancer in Iranian Women Aged Less than 40 Years Asian Pacific J Cancer Prev. 2010; 11: 17235.

33. Vaisy A, Lotfinejad S, Zhian F. Risk of Cancer with Combined Oral Contraceptive Use among Iranian Women. Asian Pac J Cancer Prev. 2014; 15 (14): 5517-22. doi: 10.7314/apjcp.2014.15.14.5517.

34. Ribeiro $\mathrm{MH}$, da Silva MA3, Muniz Filho WE, et al. Family history in breast cancer in Sao Luis, Maranhao, Brazil. BMC Res Notes. 2016; 9: 155. doi: 10.1186/s13104-015-1471-7.

35. Memon ZA, Qurrat-ul-Ain, Khan R, et al. Clinical Presentation and Frequency of Risk Factors in 
Patients with Breast Carcinoma in Pakistan. Asian Pac J Cancer Prev. 2015; 16(17): 7467-72. doi: 10.7314/apjcp.2015.16.17.7467

36. Hanf V, Hanf D. Reproduction and breast cancer risk. Breast Care (Basel). 2014; 9(6): 398-405. doi: 10.1159/000369570.

37. Sufian SN, Masroor I, Mirza W, et al. Evaluation of common risk factors for breast carcinoma in females: A hospital based study in Karachi, Pakistan. Asian Pac J Cancer Prev. 2015; 16(15): 6347-52. doi: 10.7314/apjcp.2015.16.15.6347.

38. Harhra NA, Basaleem HO. Trends of breast cancer and its management in the last twenty years in Aden and adjacent governorates, Yemen. Asian Pacific J Cancer Prev. 2012; 13(9): 4347-51. doi: 10.7314/apjcp.2012.13.8.4247.

39. Bowcock AM. Breast cancer genes. Breast J. 1997; 3(S1): 1-6. doi: https://doi.org/10.1111/j.15244741.1997.tb00200.x
40. Easton DF, Bishop DT, Ford D, et al. Genetic linkage analysis in familial breast and ovarian cancer: results from 214 families. The Breast Cancer Linkage Consortium Am J Hum Genet. 1993; 52(4): 678-701.

41. Shattuck-Eidens D1, McClure $M$, Simard J, et al. A collaborative survey of 80 mutations in the BRCA1 breast and ovarian cancer susceptibility gene. Implications for presymptomatic testing and screening. JAMA. 1995; 273(7): 535-41.

42. Petty EM, Killeen AA. BRCA1 mutation testing: Controversies and challenges. Clin Chem. 1997; 43(1): 6-8.

\section{Correspondence to Dr. Naji A. Abdullah \\ E-mail: nagiali1966@hotmail.com}

Received Jan. $22^{\text {th }} 2019$

Accepted Jun. 27 2019 